\title{
DESIGN DE SINALIZAÇÃO: feito para os usuários mas sem sua participação
}

\author{
Olivia Chiavareto Pezzin \\ Faculdade de Arquitetura e Urbanismo, USP \\ opezzin@gmail.com
}

Resumo: O design de sinalização, apesar de ter o caráter de uso coletivo e público em espaços, não contempla a participação do usuário em suas principais fases de criação (pré-design, design e pós-design). A partir da revisão bibliográfica de profissionais-autores e analisando as mudanças da área nos últimos 40 anos, percebese a informalidade na validação do projeto, em especial na fase de pós-ocupação, contrariando o paradigma da centralidade do usuário no design. Sugere-se a abrangência da caracterização do usuário, sua validação por prototipagem e a utilização dos estudos de ergodesign no pós-uso, liderado pela equipe de design responsável pelo sistema criado.

Palavras-chave: Design de sinalização, design centrado no usuário, metodologia de criação.

\begin{abstract}
The signage design, despite having the character of collective and public use in spaces, does not include user participation in their main phases of creation. From the bibliography of professional-authors is perceived informality in design validation, especially in the post-occupation, contradicting the paradigm of user-centered design. It is suggested the raise of user characterization, its project validation by prototyping and use, besides take the studies of ergodesign in post-use, led by the design team responsible for the system created.
\end{abstract}

Keywords: Signage design, user-centered design, creative methodology.

\section{INTRODUÇÃO}

Atualmente, a área do Design se baseia no paradigma da centralidade do usuário. No caso do design de sinalização esse fator aparece de forma indiscutível, pois o objetivo dos projetos é, a princípio, orientar os usuários com o intuito final de melhorar sua qualidade de vida. Nos sistemas de transportes, como metrôs e trens, a função do design de sinalização ganha importância ainda maior, pois influencia no tempo gasto, no espaço percorrido e entendido pelo usuário, além de alertá-lo para questões de segurança e comportamento. Em São Paulo, por exemplo, os mais de quatro milhões de passageiros diários do Metrô têm contato com o sistema de informação pública disponível. 
Devido a esse caráter social, os teóricos em design de sinalização e informação enfatizam a importância fundamental do usuário, para quem o projeto se destina. A centralidade no usuário - e não nas coerências internas do projeto, alheios à realidade - é vista por Jorge Frascara como condição sine qua non, além de ser uma questão ética:

É ético, porque a ética se baseia no reconhecimento do outro como diferente e respeitável em sua diferença. Não há receitas no desenho de informação: há conhecimentos aplicáveis, mas a aplicação sempre deve ser feita com intensa atenção prestada a quem nos dirigimos, para o que fazemos, onde, quando e por meio do que. (FRASCARA, 2011:9)

Apesar da destacada importância do usuário no projeto, na bibliografia de design de sinalização pode se dizer que há uma divisão teórica entre os estudos de criação (métodos e casos de projetos) e de recepção (wayfinding e avaliação de ergonomia informacional), como será visto adiante. Considerando a tradicional práxis do designer, o objetivo desse artigo é apresentar de que forma o usuário é abordado e como é inserido nos projetos, a partir de bibliografia sobre a criação de sistemas de design de sinalização.

\section{DESENVOLVIMENTO}

A bibliografia em design de sinalização mostra duas vertentes. No caso dos estudos de recepção, há uma preocupação notável com a eficiência do sistema para o usuário.

Para Baumann (2010), por exemplo, o espaço construído pode ser influenciado por: pontos de referência (marcos, obras de arte, edificações, sinalização) e dispositivos de orientação e navegação (mapas que auxiliem na navegação e direcionamento de estratégias para ir do ponto A ao B). Ou seja, o ponto crítico para que se tenha eficiência no design de sinalização e em especial, na orientação dos indivíduos, é o cuidado com a quantidade de informação que pode ser rapidamente apreendida (de acordo com o comportamento e a cognição humana):

Não os faça [os usuários] pensar: crie um sistema de comunicação visual compreensivo, claro e consistente, com mensagens concisas; mostre apenas o que é necessário: mostrar informações que são relevantes para guiar, localizar ou navegar no espaço em questão; remova informação excessiva: tire elementos desnecessários para criar um ambiente visual limpo. (BAUMANN, 2010)

Muitos autores chamam a atenção para o ruído da comunicação, a partir dos estudos em teoria da informação. Esse é um dos principais pontos de outro conceito interessante que se desenvolveu no Brasil graças aos esforços de Anamaria de Moraes (2002;2004): o ergodesign informacional (ou ainda design de sistemas informacionais).

Essa área promove estudos de usabilidade em ambientes construídos, como os de trabalho (laboral), ruas e avenidas (urbanos e públicos). Como tem o foco na ergonomia do usuário em relação ao sistema, utiliza-se de normas, como a NBR 14021 (acessibilidade no sistema de trem urbano ou metropolitano, de 2005), com a finalidade de medir a "efetividade, eficiência e satisfação com as quais usuários específicos atingem metas específicas em ambientes particulares" (MORAES, 2004). 
Desse modo, há avaliação dos aspectos objetivos (como economia de tempo para se executar uma tarefa) e subjetivos (como o conforto ambiental e confiança nas informações) do sistema.

Nesses estudos de recepção é evidente o interesse na experiência do usuário, fundamental para o desenvolvimento de métodos de avaliação dos sistemas informacionais. Desse modo, é interessante verificar de que forma a mesma questão da eficiência e da usabilidade (o foco no usuário) é apresentada na bibliografia sobre criação de design de sinalização, onde geralmente se discorre sobre métodos e etapas do projeto.

Segundo Jorge Frascara (2011:10), para que as pessoas não se sintam perdidas, frustradas, inseguras, perdendo tempo ou em perigo, é preciso criar um bom projeto de design de sinalização, que faça com que a informação seja:

- acessível (disponível de forma fácil),

- apropriada (ao conteúdo e ao usuário),

- $\quad$ atrativa (que convide à leitura ou compreensão),

- confiável (que não gere dúvidas),

- concisa (clara, sem adornos inúteis),

- completa (nem de mais nem de menos),

- relevante (ligada ao objetivo do usuário),

- $\quad$ oportuna (que esteja quando e onde o usuário precisar),

- $\quad$ compreensível (que não crie ambiguidades)

- $\quad$ e apreciada (por sua utilidade).

Todos esses itens devem ser adaptados ao perfil e às capacidades dos usuários a fim de diminuir o esforço cognitivo necessário para garantir a atenção e a participação no espaço construído, tendo em mente que "quanto mais unidades de informação [códigos] se deve processar, maior é o esforço cognitivo" (FRASCARA, 2011:12).

Notam-se fatores objetivos (quantitativos) e subjetivos (qualitativos) na percepção das características do sistema. Desse modo, é interessante investigar em que momento das etapas de criação há a obtenção de dados do usuário para que se possa adequar o sistema ao seu "esforço cognitivo". Além disso, de que forma é medida a eficiência do sistema (acessibilidade, satisfação, compreensão) e, por fim, como é prevista a interação e a validação do projeto com o usuário?

A metodologia apresentada em livros da área é fruto da experiência prática dos designers-autores, que costumam organizar seus processos em fases iterativas entre a equipe de design e o cliente. É importante lembrar que, no caso do design de sinalização, o cliente é geralmente "um conjunto de pessoas e interesses, enquanto o designer é um time de profissionais de diferentes disciplinas" (GIBSON, 2009:128). A equipe de design pode ser formada por designers trabalhando junto com arquitetos, luminotécnicos, profissionais do marketing/branding, engenheiros, construtoras e incorporadoras, designer de interiores, paisagistas, entre outros. Há um fundamental atrelamento do projeto de design de sinalização ao espaço, portanto ressalta-se cada vez mais a importância do trabalho em conjunto de designers e arquitetos: os ambientes podem ter situações de uso similares, porém, apresentam estruturas arquitetônicas e funções diferentes.

Conforme os estudos de metodologia comparada, a partir dos livros de design de sinalização, Cardoso et al. (2011) identificaram os processos envolvidos na 
realização de projetos na área. Apesar de perceberem a divisão do processo em quatro, seis, sete, oito ou dez etapas, para os autores da UFRGS, "nota-se a presença de grupos bem definidos, tais como pré-design ou planejamento; design [ou projeto] e pós-design ou implementação" (CARDOSO et al., 2011:9). Essas três grandes fases também são apontadas por Chris Calori (2007), em seu método.

É possível perceber que, durante o desenvolvimento do projeto, a divisão entre os sistemas de aplicações gráfica (cor, tipografia, pictogramas e infográficos) e ambiental (posicionamento, material, iluminação) nem sempre é explicitada separadamente. Alguns autores enfatizam questões burocráticas do pré-design (como conseguir financiamento e participar de licitações), outros apontam para a importância do briefing, das simulações e protótipos virtuais e físicos, além dos manuais de utilização (UEBELE, 2007; MOLLERUP, 2005); porém, poucos pontuam a pertinência da entrega desse manual, após uma primeira manutenção e avaliação, como faz Edo Smitshuijzen (2007).

É interessante notar como a questão do usuário, para quem o design deveria ser sempre direcionado, torna-se secundária e até mesmo desprezada pelos profissionais-autores. Durante o processo descrito nas bibliografias, sugere-se que, ao realizar o briefing do projeto, o designer deva somar informações recebidas do cliente sobre a intenção de utilização do espaço e as restrições de projeto com os dados fornecidos por arquitetos, engenheiros e outros profissionais técnicos envolvidos. A obtenção de dados detalhados e consistentes sobre necessidades, caracterização e anseios de usuários não é mencionado pelos profissionais-autores como parte do processo de design. Além disso, os autores da área divergem bastante sobre como deveria ser realizada a etapa de pós-design ou avaliação pós-uso de seus projetos instalados. Questiona-se, assim, até onde iria a participação ou expertise do designer nesse tipo de projeto.

Para alguns autores, como Mollerup (2005), Uebele (2007) e Calori (2007), a avaliação de seus projetos implantados, após um tempo de uso é importante para que o designer possa aprender com o que fez e melhorar sua própria prática em outros projetos. Assim, mesmo não recebendo formalmente para avaliar o sistema, seria interessante para o designer fazê-lo, observando diretamente a utilização dos usuários, ampliando o feedback do cliente e do arquiteto responsável. Para Chris Calori (2007:61), o momento da operação e do relacionamento do usuário com o sistema é uma oportunidade rara de aprendizado, quando efetividade e funcionalidade poderão, enfim, ser avaliadas. Segundo a autora, o cliente poderá contratar o designer para fazer um relatório de avaliação, quando os ajustes finos serão feitos e sinalizações adicionais, criadas. Porém, a autora não discorre sobre como desenvolver métodos de avaliação.

No método de projeto proposto por Cardoso et al. (2011:12) também se coloca a avaliação com cliente e usuário, para que no relatório final sejam feitas alterações e inclusões no manual. Tal prática permitiria "sanar inconsistências assim como possibilita aprendizados para novos projetos". Já Velho (2007), propõe que o projeto original tenha ajustes no momento da implantação e produção do mesmo: seria um manual "as-built", porém sem utilizar informações advindas da utilização do sistema pelos usuários. Na descrição do método de Gibson (2009), não há previsão de avaliações e feedback de usuários ou mesmo de clientes, após a revisão da instalação e com o uso. 
Como dito antes, Edo Smitshuijzen (2007) difere dos anteriores por sugerir a elaboração do manual do sistema de sinalização e a entrega da documentação para manutenções futuras, após um período de uso. Segundo Sampaio (2011), devido à complexidade de um projeto de grande porte - como em sistemas de transporte, muitas vezes construído por etapas ou trechos - o manual de referência a ser utilizado deve ser construído durante a instalação e a manutenção do design de sinalização. Assim, o manual "as-built" seria atualizado conforme fossem realizadas revisões do projeto inicial, in loco, sendo o mais fiel possível à realidade do ambiente.

Retomando a bibliografia da área, nota-se a divisão do processo de criação em três fases:

- $\quad$ Pré-design: o briefing tem importância maior, pois nele serão definidos os objetivos, hierarquização de informações, custos e prazos.

- Design: definição da linguagem gráfica, tridimensional e do conteúdo (mensagens). Simulação e protótipos.

- Pós-design: projeto executivo (manual e detalhamento), produção e fiscalização da implantação. Avaliação pós-ocupação é opcional e muitas vezes, informal.

Portanto, quase todas as decisões de design são baseadas no briefing produzido em conjunto com arquitetos e clientes, que acabam por mediar o contato com o usuário final. Já sobre um possível momento de avaliação não há consenso sobre como fazer a avaliação com o usuário e como ela alteraria o projeto, nessa fase final. Assim, o usuário é percebido como item acessório na fase de projeto/criação.

A fim de melhorar a avaliação pós-ocupação e dar subsídios às decisões de design durante o desenvolvimento dos projetos de design de sinalização, o paradigma da centralidade no usuário deveria ser considerado como condição sine qua non. Essa também é a opinião de Cardoso et al. (2011:11), ao propor um método (ainda não aplicado) que parte das necessidades dos usuários para a formulação do briefing: "Após o levantamento de requisitos dos usuários deve-se fazer uma priorização destes (...) [e então] são definidos os requisitos de projeto."

Para validar o sistema proposto, a principal estratégia dos designers está na prototipagem, virtual ou física. Porém, a validação é feita pelos clientes e técnicos: não foram encontrados relatos de pesquisas com usuários para validação dos protótipos (como se faz na produção de protótipos de embalagens). Além disso, todo o esforço de projeto, prototipagem e instalação parece estar abaixo do necessário, se as questões de pós-ocupação (operação e manutenção) forem tratadas com descaso, como aponta Craig Berger (2009:75):

Entenda as questões de pós-ocupação: limpeza, manutenção, reposição, e operações são questões significantes. Um belo sistema de sinalização que seja muito difícil de manter rapidamente será suplantado por alternativas. Incorporar tecnologias avançadas, se não existe uma estrutura de suporte, irá criar um pesadelo operacional de componentes eletrônicos caros e inutilizados.

Além disso, é possível afirmar que, nas diretrizes do projeto, o contexto espacial parece ter maior importância que o contexto cultural. Elena Capolongo (2010:17), por exemplo, resume o método de projeto do designer de sinalização: 
[É preciso] observar o problema a partir de diversos pontos de vista, partindo antes de tudo da análise do espaço, das suas características para depois chegar a uma escolha gráfica que possa trazer o máximo da função do wayfinding e ao mesmo tempo caracterizar o ambiente.

Nesse resumo, é notável a falta da caracterização das demandas dos usuários finais, tanto antes quanto depois do projeto estar finalizado; ou seja, os anseios e demandas dos operadores, mantenedores e dos usuários do sistema não tem garantias de serem considerados. Desse modo, o briefing contempla uma visão de requisitos espaciais, de custos e de imagem, a partir das informações fornecidas pelos clientes.

A questão da imagem da empresa, por exemplo, está além dos quesitos funcionais do sistema, sendo um trabalho com conceitos simbólicos que pretendem ser transmitidos pela interface do design de sinalização.

Analisando historicamente, pode-se dizer que ao longo dos últimos 40 anos, a área de design de sinalização apresentou mudanças consideráveis. A linguagem e o projeto do movimento moderno passaram do paradigma da "homogeneização democrática" para a busca por uma diferenciação de imagem no mercado. A própria demanda pelos serviços de design passou das esferas públicas (com o design de aparelhos públicos como parques, zoológicos, cidades, metrôs, trens e ônibus) para as esferas privadas (desenvolvendo o design corporativo).

Esse fenômeno, segundo Craig Berger (2007), deu-se na década de 1980, quando houve um crescimento dos empreendimentos na construção civil realizados pelo setor privado. O design corporativo tomou conta dos espaços urbanos, o que levou a uma concorrência vista como benéfica, pois teria estimulado a área e seus fornecedores (com novos materiais e métodos de fabricação), "sem falar nas vantagens que os computadores deram à produção de desenhos, gerenciamento de arquivos e cronogramas para sistemas de sinalização complexos. (BERGER, 2007:15)".

A construção civil do setor privado e os computadores pessoais também são apontados por Velho (2007) como fatores de grande mudança na área do design de sinalização. Como efeito, houve o desenvolvimento de linguagens mais flexíveis, distanciadas da "rigidez normativa dos anos 70" (VELHO, 2007:142), que enfatizassem a marca e sua experiência: elementos decorativos, informações interpretativas, aspectos lúdicos, interatividade, acessibilidade, novos materiais e processos.

Com o uso do computador no processo do design, a geração de alternativas de solução e a redução do custo e tempo do processo eram esperadas e, posteriormente, a pressão pela entrega de projetos complexos com custos baixos e qualidade alta em pouco tempo se tornou um imperativo entre todos os profissionais da área. A utilização de protótipos virtuais diminuiu custos e ampliou a concorrência. Os designers que estiveram no período de transição entre as práticas semi-artesanais e as digitais, acreditam que houve uma crescente desvalorização da hora de trabalho nesse tipo de expertise, por conta da concorrência e do acúmulo de responsabilidades encarregadas ao designer, ao longo dos anos.

Para o desenvolvimento das identidades corporativas, o design de sinalização passou a considerar com mais consciência a função de trabalhar a imagem dos locais, pois em muitos casos, como no Metrô de São Paulo, os ambientes são o principal ponto de contato entre a instituição e seus usuários. Assim, criam-se ambientes onde o 
usuário/cliente tenha uma experiência de marca memorável e fidelizadora. Para esse propósito os sistemas (gráfico, ambiental e de conteúdo) adquirem elementos personalizados como tipografia exclusiva e a inserção mais consistente da marca e das cores corporativas no ambiente.

Craig Berger (2009:71) enfatiza essa função do design de sinalização, relacionando-a com a "identidade transitória" que muitos edifícios assumem. Antes, a arquitetura era suficiente para indicar função, usos e caminhos (como a arquitetura de igrejas e cidades medievais), pois mantinham um layout e fachadas peculiares, formando uma tipologia. Isso não aconteceu, por exemplo, com o layout dos aeroportos, que foram construídos sem definir um "gênero formal". Esse fenômeno acentuou a importância do design de sinalização, em um espaço com dezenas de portas, companhias aéreas e vários terminais.

Hoje, portanto, a arquitetura é considerada insuficiente para delimitar a orientação espacial e a identidade corporativa (função simbólica) dos lugares:

“Novas terminologias como 'branding of places' e 'obsolescência funcional' surgiram para explicar e se adaptar às tendências, utilizando elementos temporários. (...) Design gráfico e branding suplantaram a arquitetura como ponto prioritário para designar identidade" (BERGER, 2009:22).

O design de sinalização, portanto, tem também a responsabilidade de construir uma imagem do local, podendo utilizar elementos históricos, culturais e da moda para melhorar a comunicação entre a instituição e seus usuários, "ajudando-os a compreender aquilo que a empresa oferece, estabelecendo as expectativas apropriadas" (SAMPAIO, 2011). Por isso, cada vez mais, são utilizadas estratégias de design de interiores (iluminação, cores e texturas diferenciadas) para marcar a identidade corporativa nos ambientes, inclusive de espaços públicos (figura 1).

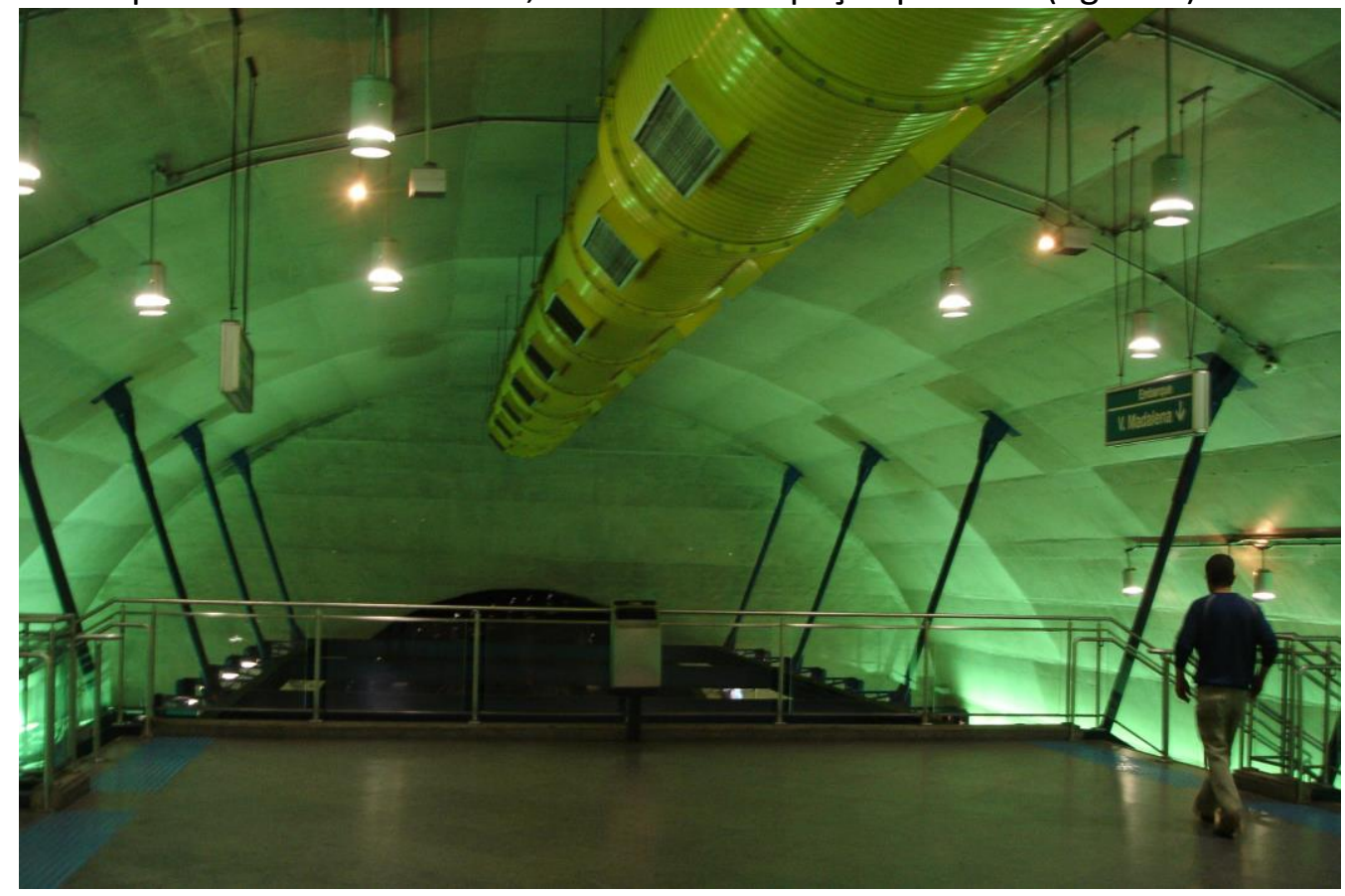

Figura 1 - Efeitos de iluminação diferenciam o ambiente na estação Alto do Ipiranga, Metrô de São Paulo. Fonte: autora. Setembro de 2012. 
Além disso, em espaços públicos, o design de sinalização também é visto como parte de uma estratégia política de renovação da paisagem urbana, como aponta Ronald Shakespear (2011:102), sobre a cidade de Buenos Aires: "Historicamente, esta paisagem se contaminou por inúmeros elementos não planejados. (...) A sinalização é a voz do lugar e formam parte da sua identidade". Outra demanda política de projetos públicos pela sinalização é criação de um "símbolo de sua presença" em regiões remotas, fornecendo informações culturais e legais. Na cidade de São Paulo e Mairiporã, há o caso da demarcação da "Linha Verde de Proteção da Serra da Cantareira", que delimitou simbolicamente um cinturão de preservação de recursos naturais da zona norte, por meio de uma sinalização de totens e painéis com a função de educar, indicar zoneamentos e trazer diretrizes para ocupação, proteção e uso do meio-ambiente da região (figura 2).

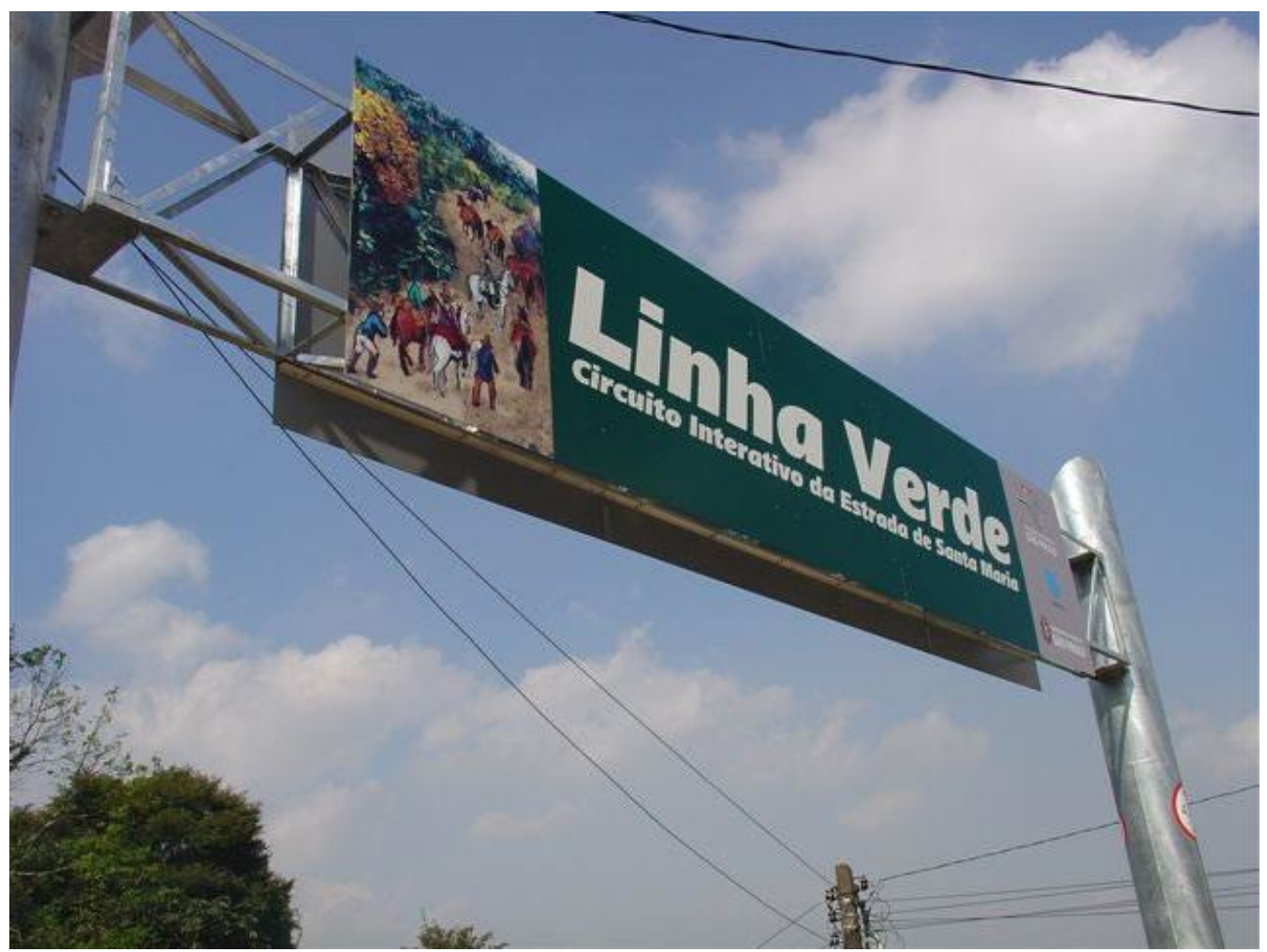

Figura 2 - pórtico demarcando o cinturão de amortecimento da zona norte de São Paulo - Linha Verde de Proteção da Serra da Cantareira. Projeto LABIM/FAU/USP. Fonte: www.arcomodular.com.br/

Outra questão em voga é a sustentabilidade desses sistemas, em geral, extremamente caros em ambientes complexos. Em se tratando de locais públicos, a resistência do sistema ao vandalismo e às intempéries são os principais requisitos, pois geram economia para a manutenção. Para Gibson (2009:122-124), é preciso considerar como premissa do design de sinalização: longevidade, flexibilidade e adaptabilidade. Em caso de ambientes temporários, como feiras e exposições, o autor enfatiza a importância de considerar a desconstrução dos sistemas. É preciso, portanto, ampla pesquisa de materiais e processos de montagem.

Apesar da importância e abrangência coletiva do design de sinalização, nos casos estudados e apresentados na bibliografia nota-se apenas a forte presença do 
cliente (quem encomenda o projeto de design) durante todas as fases do processo de criação do design de sinalização, por meio de feedbacks e aprovações (Velho, 2007). Durante o briefing, o usuário só ganharia importância se fosse considerado um requisito, pelo cliente "esclarecido". Se não há a demanda de considerar o usuário específico para o local, com intensa pesquisa, então caberá ao designer adequar o espaço físico à capacidade cognitiva de um usuário ou operador que ele não caracteriza profundamente, assim, um usuário genérico. 0 processo, então, acaba direcionando o resultado final para o atendimento dos anseios deste cliente e não necessariamente para os usuários do ambiente em questão.

Apesar dessa constatação, partindo dos estudos de Velho (2007), Zeng (2011), Rüetschi e Timpf (2005), é possível sugerir uma participação maior do usuário na metodologia do design de sinalização, considerando as três principais fases do projeto, a ser liderada pelos próprios designers:

- $\quad$ Pré-design - No briefing, há uma forte influência do cliente, porém, o designer deve lembrar-se de representar também os interesses do usuário, procurando referenciá-lo o máximo possível.

- Design - há uma forte pressão pela aprovação rápida do projeto, por isso há uma ênfase cada vez maior no fornecimento de múltiplas alternativas e protótipos virtuais, ou seja, na apresentação do projeto. Pode ser proveitoso inserir o usuário também na validação dos protótipos.

- $\quad$ Pós-design - A tendência do mercado fornecedor de materiais é a de

diminuir custos de produção, no entanto deve se ter em conta a longevidade e manutenção dos sistemas; $\mathrm{Na}$ fase final, o designer deveria tomar para si o questionamento da eficiência dos sistemas de sinalização instalados, em especial em locais públicos de trânsito, com o desenvolvimento de metodologias específicas de avaliação, que poderiam ser adicionadas como parte finalíssima do processo, tal como os estudos de pós-ocupação em arquitetura.

Reitera-se a importância de considerar a fase pós-ocupação ou "pós-uso" como parte do processo e das responsabilidades a cargo do designer, com a finalidade de ampliar as definições da etapa de verificação, nos projetos em design de sinalização. Dessa forma, o designer poderia apresentar em seu portfólio não apenas as propostas produzidas, mas também os resultados atingidos por elas, corroborando a ideia de que o design, assim como a comunicação, acontece durante o momento de seu uso.

Essa fase "pós-uso" seria tratada pelo designer como o momento das correções e também de constatações (estatísticas como melhorias no fluxo, percepção da imagem do cliente pelo usuários, aumento da satisfação do usuário) e recomendações para a manutenção do sistema. Jorge Frascara (2011:49) também aponta a avaliação como estratégia para que o designer apresente dados concretos, medidos, sobre os resultados e a eficiência de seus projetos. Isso seria benéfico para o próprio designer, que poderia aprender com as revisões, para o Design (com a ampliação do entendimento das responsabilidades do designer) e para a experiência do usuário (que de fato interage com os dispositivos criados, e tem a vida cotidiana afetada por eles).

\section{CONCLUSÃO}

Apesar do paradigma da centralidade do usuário e do caráter de uso coletivo e público dos projetos em design de sinalização, sua metodologia de criação não 
contempla a participação do usuário nas fases do processo, pois geralmente não se realizam testes de usabilidade e o projeto é finalizado sem sua validação.

As mudanças na área ao longo dos últimos quarenta anos mostram a crescente versatilidade e rapidez produtiva para oferecer soluções que atendam e sejam aprovadas apenas pelos clientes. A avaliação pós-ocupação não é vista como obrigatória no processo de design de sinalização. Vários autores da bibliografia pesquisada apontam como ponto final a entrega do projeto e seu manual (apenas um deles aponta para a entrega do manual após um período de experiência com o sistema). No entanto, a avaliação é vista como interessante para que o designer, mesmo que informalmente, conheça os resultados de sua ação/projeto. Geralmente, para efeito de medição de satisfação e/ou eficiência, são realizados estudos de ergonomia ambiental ou informativa com outros profissionais. Assim, a responsabilidade do designer é entregar algo cuja eficiência ele desconhece a priori e não se envolve formalmente $a$ posteriori.

Analisando os momentos em que informações sobre ou dos usuários são recebidas é possível perceber que

a. na fase de briefing, o cliente é quem passa as informações sobre o usuário. Não há em geral, pesquisas aprofundadas sobre o comportamento e necessidades específicas em relação àquele tipo de ambiente. Pesquisas etnográficas não são consideradas. Consideramse as necessidades genéricas de usuários-tipo (idosos, deficientes, etc.). Informações sobre o ambiente também são passadas pelo cliente.

b. Na fase de projeto, em especial na prototipagem, o usuário não é chamado a participar.

c. Na fase de execução, a avaliação pós-ocupação é opcional e informal.

Ou seja, o usuário do sistema, para quem o projeto é criado e deveria ser "centrado", não tem a sua participação nas principais fases. Apenas em situações de conflito ou ineficiência, procura-se descobrir o que "deu errado", resultando muitas vezes em improvisos na tentativa de melhorar a comunicação de um sistema que em geral, dada sua complexidade, é de cara manutenção.

\section{REFERÊNCIAS}

BAUMANN, Sander. Intoduction to wayfinding and signage design. Disponível em $<$ www.designworkplan.com/wayfinding/introduction.htm>.Publicado em 17.nov.2010. acessado em 10.mai.2011.

BERGER, Craig M. Wayfinding. Designing and Implementing Graphic Navigational Systems. Mies: Rotovision, 2009.

CALORI, C. Signage and Wayfinding Design: A complete Guide to Creating Environmental Graphic Design Systems. Nova Iorque: Wiley John \& Sons, 2007.

CAPOLONGO, Elena. Wayfinding in Design. Progetto per la segnaletica della facoltà di design del Politecnico di Milano. Tese di Laurea Specialistica in Design della Comunicazione. Milão: POLIMI, 2010.

CARDOSO, Eduardo Cardoso; SCHERER, Fabiano de Vargas; TEIXEIRA, Fabio; SILVA, Régio e DA SILVA, Tania Kolterman. Design de Sinalização: representações gráficas 
como ferramenta de análise para contribuição metodológica. 5o Congresso Internacional de Design da Informação. UFSC: Florianópolis, 2011.

FRASCARA, J. Que és el diseño de comunicación? Buenos Aires: Ediciones Infinito, 2011.

GIBSON, D. The Wayfinding Handbook: Information Design for Public Places. Nova lorque: Princeton Architectural Press, 2009.

MOLLERUP, Per. Wayshowing: a guide to environmental signage. Baden: Lars Müller Publishers, 2005.

MORAES, Anamaria de. (org) Avisos, advertências e projetos de sinalização. Rio de Janeiro: iUsEr, 2002.

MORAES, Anamaria de (Org.). Ergodesign do ambiente construído e habitado: ambiente urbano, ambiente público, ambiente laboral. Rio de Janeiro: iUsEr, 2004.

RÜETSCHI, U.; TIMPF, S. U-J. Modelling Wayfinding in Public Transport: Network Space and Scene Space. SC'04 Proceedings of the 4th international conference on Spatial Cognition: reasoning, Action, Interaction. Springer-Verlag: Berlim, 2005.

SAMPAIO, Cláudio P. Sinalização e design de superfície. Aulas do curso de design gráfico. Londrina: UEL, 2011. Disponível em <https://sites.google.com/site/claudiopereiradesign/sinalizacao>. Acessado em nov. 2011.

SHAKESPEAR, R. El diseño como catalizador. In: FRASCARA, J. Qué es el diseño de información? Buenos Aires: Ediciones infinito, 2011.

SMITSHUIJZEN, Edo. Signage Design Manual. Baden: Lars Müller Publishers,2007.

UEBELE, Andreas. Signage Systems and information graphics. Londres:

Thames\&Hudson,2006.

VELHO, A.L.O.L.; MAGALHÃES, C. F. O design de sinalização no Brasil: a introdução de novos conceitos de 1970 a 2000. Dissertação de mestrado em Artes e Design. PUC-Rio, 2007.

ZENG, Qingjie. Performance Evaluation of Signage System in Subway Stations.

Dissertação de mestrado em engenharia civil. Montreal: Universidade de Concordia, 2011. 